\title{
Band gap structure modification of amorphous anodic Al oxide film by Ti-alloying
}

Canulescu, Stela; Rechendorff, K.; Borca, C. N.; Jones, N. C.; Bordo, Kirill; Schou, Jørgen; Nielsen, Lars Pleth; Hoffmann, S. V.; Ambat, Rajan

Published in:

Applied Physics Letters

Link to article, DOI:

$10.1063 / 1.4866901$

Publication date:

2014

Document Version

Publisher's PDF, also known as Version of record

Link back to DTU Orbit

Citation (APA):

Canulescu, S., Rechendorff, K., Borca, C. N., Jones, N. C., Bordo, K., Schou, J., Nielsen, L. P., Hoffmann, S. V., \& Ambat, R. (2014). Band gap structure modification of amorphous anodic Al oxide film by Ti-alloying. Applied Physics Letters, 104(12), [121910]. https://doi.org/10.1063/1.4866901

\section{General rights}

Copyright and moral rights for the publications made accessible in the public portal are retained by the authors and/or other copyright owners and it is a condition of accessing publications that users recognise and abide by the legal requirements associated with these rights.

- Users may download and print one copy of any publication from the public portal for the purpose of private study or research.

- You may not further distribute the material or use it for any profit-making activity or commercial gain

- You may freely distribute the URL identifying the publication in the public portal 


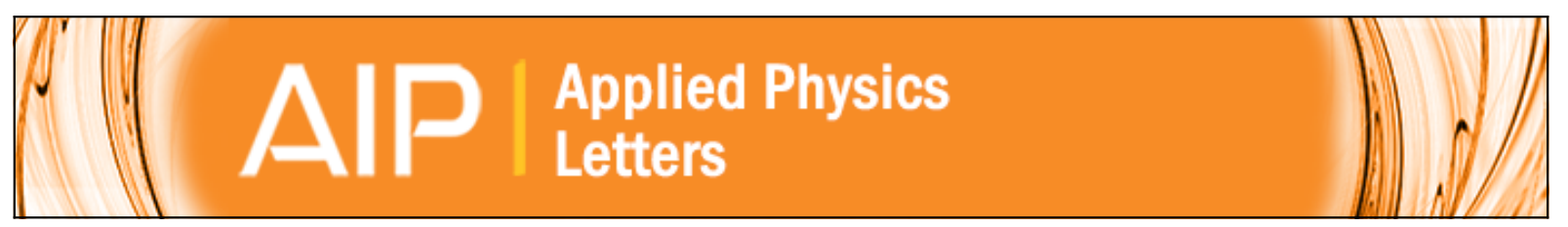

\section{Band gap structure modification of amorphous anodic Al oxide film by Ti-alloying}

S. Canulescu, K. Rechendorff, C. N. Borca, N. C. Jones, K. Bordo, J. Schou, L. Pleth Nielsen, S. V. Hoffmann, and R. Ambat

Citation: Applied Physics Letters 104, 121910 (2014); doi: 10.1063/1.4866901

View online: http://dx.doi.org/10.1063/1.4866901

View Table of Contents: http://scitation.aip.org/content/aip/journal/apl/104/12?ver=pdfcov

Published by the AIP Publishing

\section{Articles you may be interested in}

Anodic formation of highly ordered $\mathrm{TiO} 2$ nanotube arrays on conducting glass substrate: Effect of titanium film thickness

J. Vac. Sci. Technol. A 33, 061402 (2015); 10.1116/1.4926752

Electrochromism and small-polaron hopping in oxygen deficient and lithium intercalated amorphous tungsten oxide films

J. Appl. Phys. 118, 024901 (2015); 10.1063/1.4926488

Band gap modulation of ZnTe1-xOx alloy film by control of oxygen gas flow rate during reactive magnetron sputtering

Appl. Phys. Lett. 103, 263901 (2013); 10.1063/1.4856375

Optical characteristics of pulsed laser deposited $\mathrm{Ba} 0.8 \mathrm{Sr} 0.2 \mathrm{TiO} 3$ thin films grown on fused quartz substrate AIP Conf. Proc. 1451, 139 (2012); 10.1063/1.4732393

Band structure modification of Al oxide by Ti-alloying and magnetoresistance behavior of magnetic tunnel junctions with Ti-alloyed Al oxide barrier

Appl. Phys. Lett. 86, 252501 (2005); 10.1063/1.1949726

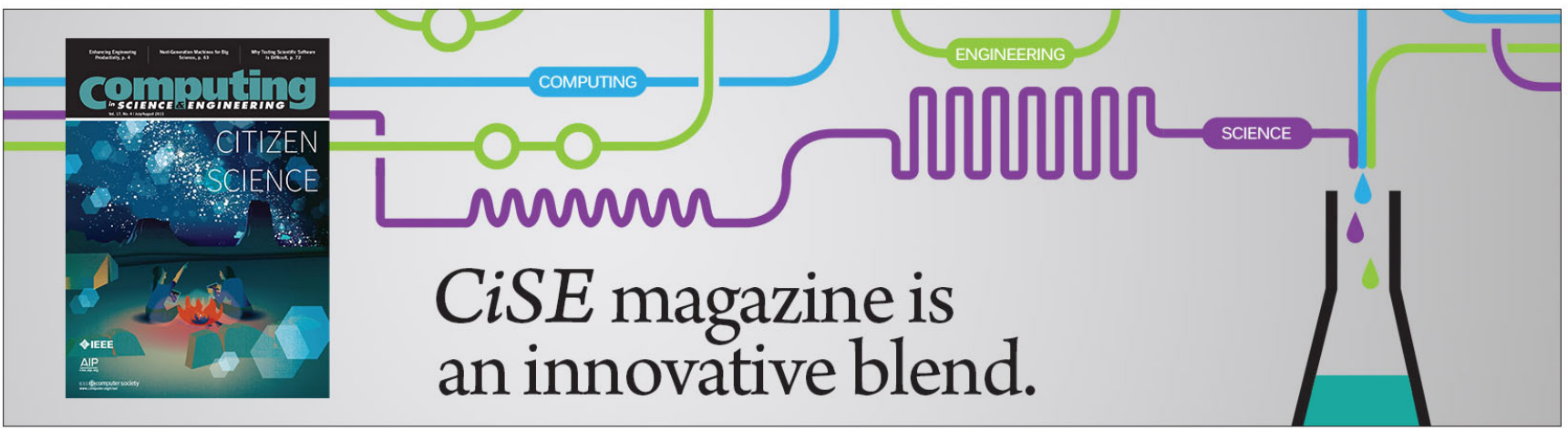




\title{
Band gap structure modification of amorphous anodic Al oxide film by Ti-alloying
}

\author{
S. Canulescu, ${ }^{1, a)}$ K. Rechendorff, ${ }^{2}$ C. N. Borca, ${ }^{3}$ N. C. Jones, ${ }^{4}$ K. Bordo, ${ }^{5}$ J. Schou, ${ }^{1}$ \\ L. Pleth Nielsen, ${ }^{2}$ S. V. Hoffmann, ${ }^{4}$ and R. Ambat ${ }^{5}$ \\ ${ }^{1}$ Department of Photonics Engineering, Technical University of Denmark, 4000 Roskilde, Denmark \\ ${ }^{2}$ Danish Technological Institute, Kongsvang Alle 29, 8000 Aarhus, Denmark \\ ${ }^{3}$ Paul Scherrer Institute, 5232 Villigen, Switzerland \\ ${ }^{4}$ ISA, Department of Physics and Astronomy, Aarhus University, 8000 Aarhus, Denmark \\ ${ }^{5}$ Department of Mechanical Engineering, Technical University of Denmark, 2800 Kongens Lyngby, Denmark
}

(Received 21 January 2014; accepted 10 February 2014; published online 27 March 2014)

\begin{abstract}
The band structure of pure and Ti-alloyed anodic aluminum oxide has been examined as a function of Ti concentration varying from 2 to 20 at. \%. The band gap energy of Ti-alloyed anodic Al oxide decreases with increasing $\mathrm{Ti}$ concentration. X-ray absorption spectroscopy reveals that $\mathrm{Ti}$ atoms are not located in a $\mathrm{TiO}_{2}$ unit in the oxide layer, but rather in a mixed Ti-Al oxide layer. The optical band gap energy of the anodic oxide layers was determined by vacuum ultraviolet spectroscopy in the energy range from 4.1 to $9.2 \mathrm{eV}(300-135 \mathrm{~nm})$. The results indicate that amorphous anodic $\mathrm{Al}_{2} \mathrm{O}_{3}$ has a direct band gap of $7.3 \mathrm{eV}$, which is about $\sim 1.4 \mathrm{eV}$ lower than its crystalline counterpart (single-crystal $\mathrm{Al}_{2} \mathrm{O}_{3}$ ). Upon Ti-alloying, extra bands appear within the band gap of amorphous $\mathrm{Al}_{2} \mathrm{O}_{3}$, mainly caused by Ti $3 \mathrm{~d}$ orbitals localized at the Ti site. $(\mathrm{C} 2014$ AIP Publishing LLC. [http://dx.doi.org/10.1063/1.4866901]
\end{abstract}

Amorphous anodic aluminum oxides (AAO) have received large interest in materials science as they are key materials in many applications such as metal-oxide semiconductor devices, ${ }^{1}$ dye-sensitized solar cells, ${ }^{2}$ or corrosion protection. Due to the possibility of tuning the band gap, dielectric constant, conductivity, and even optical appearance by alloying, ${ }^{3}$ amorphous anodic oxides are interesting from both theoretical and practical viewpoints. However, studies on the modification of the band gap structure of the amorphous anodic layers upon alloying are rather limited. Semi-empirical correlation between the electronegativity and band gap of oxides has been used recently to estimate the band gap of mixed metal oxides. ${ }^{4,5}$ While anodic $\mathrm{Al}$ oxide layers are widely used, few studies on band gap structure of anodic oxide films have been reported. ${ }^{5}$

In this Letter, we study the effect of Ti alloying on the electronic structure and band gap states of amorphous anodic aluminum oxide. We analyze the local environment of $\mathrm{Ti}$ atoms in the mixed $\mathrm{Ti}$-Al oxide films by means of X-ray absorption spectroscopy (XAS), and we determine the band gap energy of Ti-alloyed anodic aluminum oxide by vacuum ultraviolet (VUV) spectroscopy.

Thin films of Ti-Al alloys, with Ti concentration ranging from 2 to 20 at. \%, were deposited at room temperature by DC magnetron sputtering on double-side polished sapphire substrates. The deposition was carried out using two $\mathrm{Al}$ and two Ti targets (99.99\% purity). The film composition was adjusted by changing the relative power on the $\mathrm{Al}$ and Ti targets, keeping the total power constant, while the sputtering time was appropriately set in order to deposit films of similar thickness $\sim 130 \mathrm{~nm}$. The anodizing was performed in a dualelectrode cell, where an Al-Ti film on sapphire served as the anode and a Pt mesh served as the cathode. All films were

a)Electronic mail: stec@fotonik.dtu.dk. anodized in $20 \%$ sulphuric acid at a constant voltage of $20 \mathrm{~V}$ at $18^{\circ} \mathrm{C}$. The anodizing was stopped when the observed current density was stabilized at $0.1 \mathrm{~mA} / \mathrm{cm}^{2}$. All anodized samples show high transparency in the visible spectra range. The films were not sealed after anodizing, such that the anodized layer consists of a porous structure with open pores.

$\mathrm{X}$-ray absorption spectra at the Ti K-edge were measured at the microXAS beamline at the Swiss Light Source (Switzerland) using a Si (111) double-crystal monochromator with an energy resolution close to the intrinsic (111) crystal reflection. The X-ray beam size was $500 \times 500 \mu \mathrm{m}^{2}$. The films were measured in fluorescence mode, while powder references were measured in transmission mode. The energy shifts between the various spectra were established by comparison with spectra obtained from the appropriate reference compounds. After background subtraction, all spectra were normalized to unity at $400 \mathrm{eV}$ above the Ti K-edge.

VUV spectroscopy in the energy range from 4.1 to $9.2 \mathrm{eV}(300-135 \mathrm{~nm})$ was used to probe the valence to conduction band transitions. Transmittance measurements were carried out at the CD1 beamline of the ASTRID Synchrotron Light Source (Denmark) in a $\mathrm{N}_{2}$ purged chamber to avoid absorption of the UV light by air molecules. A baseline was acquired each time before and after the measurement. The measurements from 6.2 to $2.1 \mathrm{eV}(200-600 \mathrm{~nm})$ were taken using a UV-visible spectrometer (model Cary 50). The results from the VUV and UV-visible spectrometer agreed well in the overlapping energy region from 200 to $300 \mathrm{~nm}$, and the data were spliced together without the need to use a multiplicative scaling factor.

The local electronic structure of anodized Ti-alloyed $\mathrm{Al}$ oxides (2, 10, and 20 at. \% Ti) and reference compounds was investigated using XAS at the Ti K-edge, and the results are shown in Fig. 1(a). The XAS measurements were performed in fluorescence mode, in which the emitted Ti $\mathrm{K} \alpha_{1,2}$ photons 

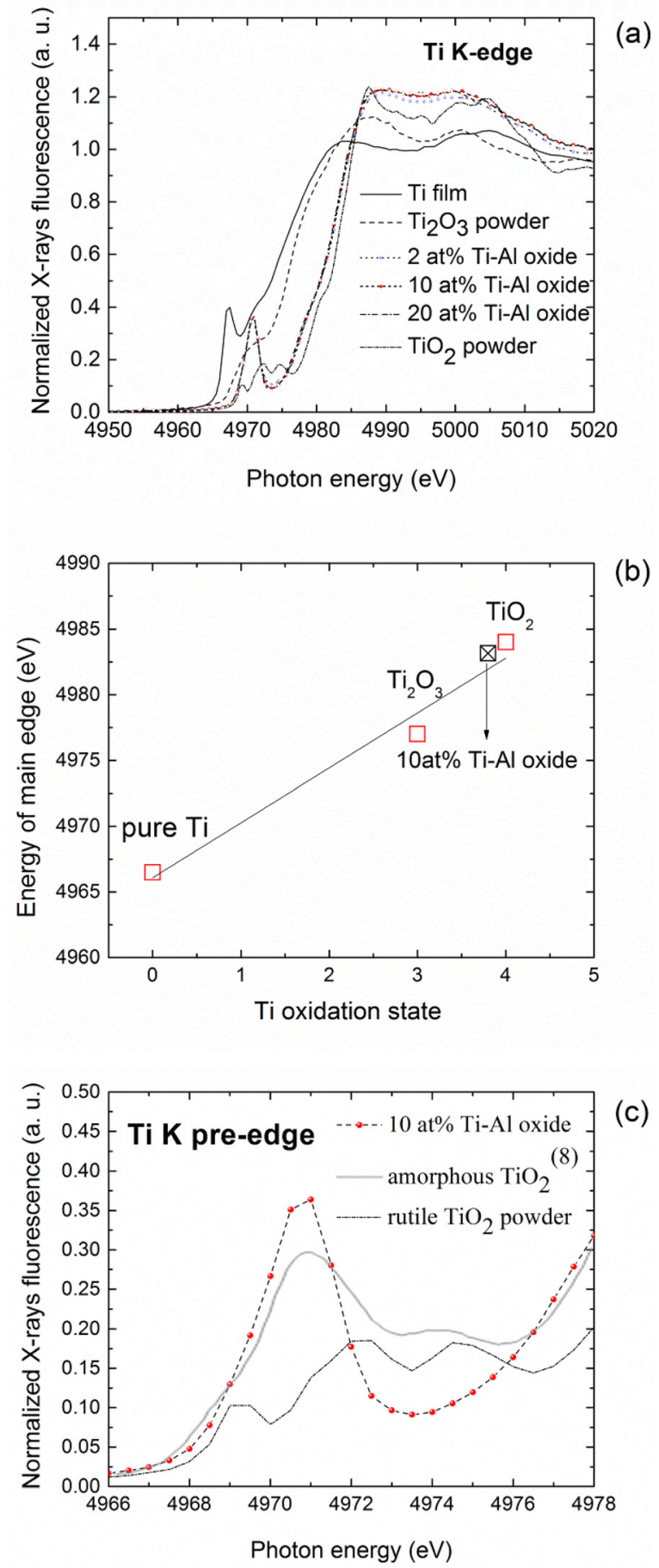

FIG. 1. (a) XAS spectra of sputter-deposited Ti film, $\mathrm{Ti}_{2} \mathrm{O}_{3}$ powder, $\mathrm{TiO}_{2}$ rutile powder, and 2, 10, and 20 at. \% Ti-Al oxide at the Ti K-edge; (b) the position of the Ti K-edge as a function of Ti oxidation state, as determined from the XAS spectra; (c) XAS spectra at the Ti K pre-edge for 10 at. \% Ti-Al oxide together with reference spectra of rutile and amorphous $\mathrm{TiO}_{2}$. Reproduced by permission from Borghols et al., J. Electrochem. Soc. 157, A582 (2010). Copyright 2010 by The Electrochemical Society. ${ }^{8}$

were collected along the X-ray probing depth (at $5 \mathrm{keV}$ ) of several tens of microns. As the average thickness of films is $130 \mathrm{~nm}$, the XAS analysis reveals the bulk electronic structure of the film, and surface effects can be neglected. The main absorption edge of the anodized Ti-Al oxide alloy is located at lower energy compared to the one of rutile $\mathrm{TiO}_{2}$ (Fig. 1(a)). The energy of the main absorption edge is very sensitive to the actual chemical valence of the excited atom, ${ }^{6,7}$ and a systematic shift to higher energy corresponds to an increase of the oxidation state. In Fig. 1(b), the energy of the main edge of 10 at. \% Ti-alloyed $\mathrm{Al}$ oxide is compared to the well-known titanium reference compounds, i.e., Ti foil $\left(\mathrm{Ti}^{0}\right), \mathrm{Ti}_{2} \mathrm{O}_{3}\left(\mathrm{Ti}^{3+}\right)$, and rutile $\mathrm{TiO}_{2}\left(\mathrm{Ti}^{4+}\right)$. An average valence of $\mathrm{Ti}$ of 3.8 was estimated based on the linear interpolation, indicating that $\mathrm{Ti}$ atoms have a mixed valence state between $3+$ and $4+$ in the anodized layer. No change of the Ti K-edge spectra was observed with increasing Ti alloying from 2 to 20 at. \%. This suggests that the valence state and local atomic environment around the $\mathrm{Ti}$ atoms do not change with the amount of Ti alloying.

The pre-edge features of the $\mathrm{Ti} \mathrm{K}$-edge shown in Fig. 1(c) represent the discrete electronic excitations into unoccupied (bound) states. The pre-edge features of Ti-Al oxides are compared with those of rutile and amorphous $\mathrm{TiO}_{2}{ }^{8} \mathrm{X}$-ray diffraction analyses reveal that the anodized Ti-Al oxide layers have an amorphous structure (not presented here), so the spectrum of amorphous $\mathrm{TiO}_{2}$ is also included for comparison. Three pre-edge peaks of the $\mathrm{TiO}_{2}$ rutile indicate the presence of the $\mathrm{TiO}_{6}$ octahedron, which is characteristic to all crystalline forms of $\mathrm{TiO}_{2} .{ }^{8}$ The first two pre-peaks are associated with transitions of the excited core electrons to the $3 \mathrm{~d}-\mathrm{t}_{2 \mathrm{~g}}$ non-bonding bands, whereas the third peak is a signature of the transition to the $3 \mathrm{~d}-\mathrm{e}_{\mathrm{g}}$ anti-bonding band. Amorphous $\mathrm{TiO}_{2}$ resembles a strongly deformed octahedron which modifies the local atomic distribution of ions around the $\mathrm{Ti}$, and thus, the shape and the intensity of the pre-edge peaks are completely modified compared to the crystalline form. The pre-edge spectra of the amorphous Ti-Al oxides resemble neither a rutile nor an amorphous $\mathrm{TiO}_{2}$ spectrum suggesting that the $\mathrm{Ti}$ atoms are not located in a $\mathrm{TiO}_{2}$ unit but rather in a mixed Ti-Al oxide matrix. Previous results on anodic films on $\mathrm{Al}-25$ at. $\% \mathrm{Ti}^{9}$ and Al-51 at. $\% \mathrm{Ti}^{10}$ indicate that the anodized layer contains units of $\mathrm{TiO}_{2}$ and $\mathrm{Al}_{2} \mathrm{O}_{3}$. However, the XAS analysis in this work does not reveal the presence of $\mathrm{TiO}_{2}$ units. A possible explanation of this discrepancy could be the lower amount of Ti (up to 20\%) in the samples used in this study.

VUV spectroscopy has been employed to study the electronic structure of pure and Ti-alloyed anodic aluminum oxide.

The theoretical expression of the absorption coefficient, $\alpha$, for direct optical transitions is related to the incident photon energy $(\mathrm{h} \nu)$ by the relation ${ }^{11,12}$

$$
(\alpha \mathrm{E})^{2} \sim \mathrm{A}\left(\mathrm{E}-\mathrm{E}_{\mathrm{g}}\right)
$$

where $\mathrm{A}$ is a constant depending on the transition probability. The band gap energy can then be determined by extrapolating $(\alpha \mathrm{E})^{2}$ to zero. The optical band gap plot of anodized aluminum oxide film on sapphire is shown in Fig. 2, together with the band gap plot for sapphire included for comparison in the inset. Here, we assumed that all incident light is either transmitted or absorbed, with reflection or scattering being negligible. $^{13}$

Sapphire (single-crystal $\mathrm{Al}_{2} \mathrm{O}_{3}$ ) shows a dramatic cut-off in transmittance at around $8.7 \mathrm{eV}$, corresponding to the optical band gap energy (see inset in Fig. 2). The measured band gap energy is in close agreement with the reported value of 


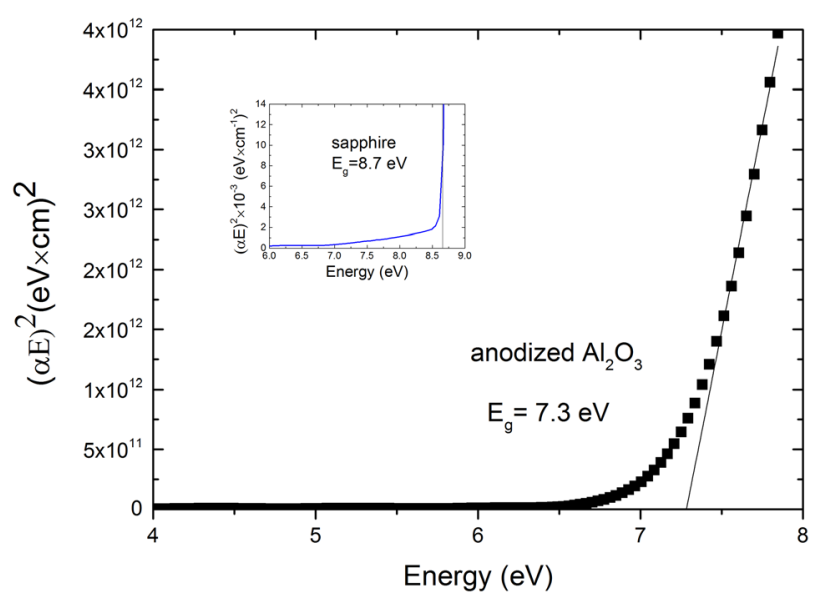

FIG. 2. Optical band gap plot of the anodized $\mathrm{Al}_{2} \mathrm{O}_{3}$ film on sapphire. Inset represents the band gap plot of sapphire (single crystal of $\mathrm{Al}_{2} \mathrm{O}_{3}$ ).

single-crystal $\mathrm{Al}_{2} \mathrm{O}_{3}$, i.e., $8.8 \mathrm{eV} .^{11}$ Anodic $\mathrm{Al}$ oxide has a band gap value of $7.3 \mathrm{eV}$, as determined assuming direct optical transitions, which matches the experimental values of $\gamma-\mathrm{Al}_{2} \mathrm{O}_{3}$ (7.2 eV) (Ref. 11) well. Our results indicate a decrease in the band gap energy as one goes from a crystalline to amorphous $\mathrm{Al}_{2} \mathrm{O}_{3}$. The reduction in the band gap energy of amorphous oxide is attributed to the presence of unoccupied states within the band gap. These unoccupied states have been associated with oxygen vacancies that act as electron and hole traps ${ }^{14}$ in amorphous $\mathrm{Al}_{2} \mathrm{O}_{3}$ grown by Atomic Layer Deposition (ALD). A band tail of $6.4 \mathrm{eV}$ is observed. Anodized aluminum oxide has an amorphous structure ( similar to ALD-deposited $\mathrm{Al}_{2} \mathrm{O}_{3}$ ), but with pores of $15 \mathrm{~nm}$ and with a typical inter-pore distance around $100 \mathrm{~nm} .{ }^{15}$ The degree of lattice distortion is therefore likely to be higher for these nano-porous anodic films, thus causing aggregation of vacancies acting as trap states along the walls of the pores and leading to lower band-to-band transition energy. $^{13}$

Upon alloying with $\mathrm{Ti}$, modifications of the microstructure, as well of the electronic structure of the amorphous anodic films are produced. Fig. 3 shows the variation of the absorption at the band gap for thin films of Ti-alloyed $\mathrm{Al}$ oxide. The band gap energy of anodic Ti-Al oxide decreases with increasing $\mathrm{Ti}$ content. The determined experimental

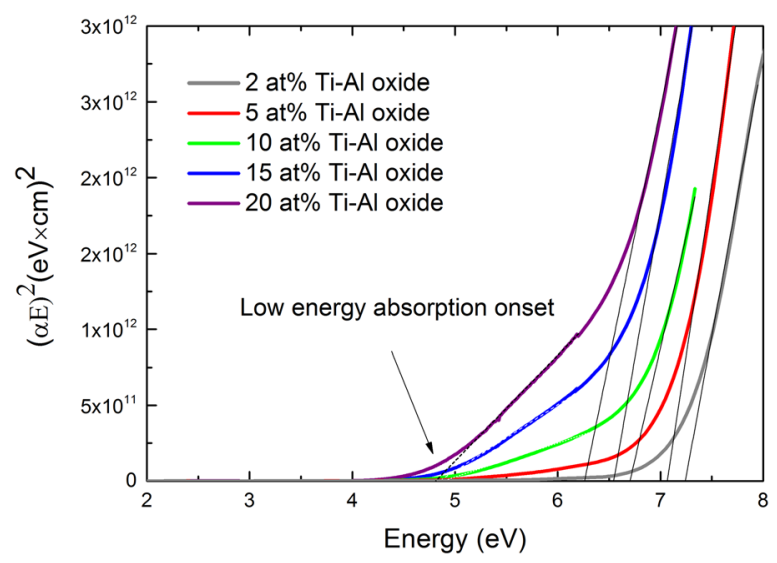

FIG. 3. Plots of $(\alpha h \nu)^{2}$ versus $h \nu$ for the Ti-alloyed Al oxide films with Ti concentrations varying from 2 to 20 at. $\%$. values of band gap energy are given in Table I. The valence band consists of occupied $\mathrm{O} 2 \mathrm{p}$ orbitals and the conduction band of $\mathrm{Al} 3 \mathrm{~s}-3 \mathrm{p}$ empty orbitals, ${ }^{11}$ therefore the optical band gap in $\mathrm{Al}_{2} \mathrm{O}_{3}$ originates from $\mathrm{O} 2 \mathrm{p}$ to $\mathrm{Al} 3 \mathrm{~s}$ transitions. When the $\mathrm{Ti}$ ions are present at the $\mathrm{Al}$ site, extra bands appear within the band gap of $\mathrm{Al}_{2} \mathrm{O}_{3}$ below the conduction band. First principle pseudopotential calculations have shown that these bands are mainly composed of Ti $3 d$ orbitals localized around the Ti sites. ${ }^{16}$ The interaction between the $\mathrm{Al}_{2} \mathrm{O}_{3}$ band electrons and localized $3 \mathrm{~d}$-electrons associated with $\mathrm{Ti}$ atoms leads to a change in the conduction band (CB) and valence band (VB) energy levels, causing the band gap to shrink. The experimentally determined band gap energy decreases by about $1.1 \mathrm{eV}$ from the pure to 20 at. $\%$ Ti alloyed $\mathrm{Al}$ oxide (Table I). The reduction in the band gap energy of $\mathrm{Al}_{2} \mathrm{O}_{3}$ was also reported experimentally for other transition metal-alloyed $\mathrm{Al}_{2} \mathrm{O}_{3}$, such as $\mathrm{Nb}$ and $\mathrm{Zr}$. A reduction in the band gap energy of $2.3 \mathrm{eV}$ and $0.8 \mathrm{eV}$ was estimated for 6.25 at. $\% \mathrm{Nb}$ - and $\mathrm{Zr}$-alloyed $\mathrm{Al}_{2} \mathrm{O}_{3}$, respectively. ${ }^{3}$ Thus, we have confirmed experimentally the decrease in the band gap upon Ti-alloying, which is in agreement with the introduction of extra $\mathrm{Ti} 3 \mathrm{~d}$ bands within the band gap of $\mathrm{Al}_{2} \mathrm{O}_{3}$.

A low-energy absorption feature for the highest Ti-alloyed Al oxide films can be observed in Fig. 3. The onset of low-energy absorption is rather similar $(\sim 4.8 \mathrm{eV})$ suggesting that the origin of the optical transitions is the same. However, the area under the low-energy absorption region increases linearly with $\mathrm{Ti}$ content due to the replacement of Al states with Ti states. This feature could indicate the formation of Ti-derived band states near the conduction band gap edge. States introduced by Ti alloying overlap at high titanium concentration and evolve as an impurity band. Therefore, the low-energy absorption onset is most likely caused by electron transitions from the valence band to Ti-derived impurity states located within the band gap of amorphous anodic aluminum oxide.

In summary, we have studied the optical and electronic structure properties of anodized $\mathrm{Al}$ oxide and Ti-alloyed $\mathrm{Al}$ oxide over a wide Ti composition range (up to 20 at. \%). Xray absorption spectroscopy at $\mathrm{Ti} \mathrm{K}$-edge reveals that $\mathrm{Ti}$ atoms are not located in $\mathrm{TiO}_{2}$ unit, but in an Al-Ti oxide with mixed $\mathrm{Ti}^{3+} / \mathrm{Ti}^{4+}$ valence states and an effective valence of 3.8. Vacuum ultraviolet spectroscopy of these films shows that the band gap structure is closely related to the crystal structure of the films, such that amorphous anodized $\mathrm{Al}$ oxide

TABLE I. Band gap energy values of $\mathrm{Al}$ oxide and Ti-alloyed $\mathrm{Al}$ oxide.

\begin{tabular}{lc}
\hline \hline Alloy & Band gap energy, $\mathrm{E}_{\mathrm{g}}{ }^{\text {opt }}(\mathrm{eV})$ \\
\hline Single crystal $\mathrm{Al}_{2} \mathrm{O}_{3}$ (sapphire) & $8.7 \mathrm{eV}$ \\
Anodised $\mathrm{Al}_{2} \mathrm{O}_{3}$ & $7.3 \mathrm{eV}$ \\
2 at. \% Ti-alloyed $\mathrm{Al}_{2} \mathrm{O}_{3}$ & $7.2 \mathrm{eV}$ \\
5 at. \% Ti-alloyed $\mathrm{Al}_{2} \mathrm{O}_{3}$ & $7 \mathrm{eV}$ \\
10 at. \% Ti-alloyed $\mathrm{Al}_{2} \mathrm{O}_{3}$ & $6.7 \mathrm{eV}$ \\
15 at. \% Ti-alloyed $\mathrm{Al}_{2} \mathrm{O}_{3}$ & $6.5 \mathrm{eV}$ \\
20 at. \% Ti-alloyed $\mathrm{Al}_{2} \mathrm{O}_{3}$ & $6.2 \mathrm{eV}$ \\
Anodised $\mathrm{TiO}_{2}{ }^{\mathrm{a}}$ & $3.4 \mathrm{eV}$ \\
\hline
\end{tabular}

${ }^{\mathrm{a}}$ Reference 13. 
has a direct band gap energy which is about $1.4 \mathrm{eV}$ lower than its crystalline counterpart. Upon Ti-alloying, extra bands appear within the band gap of amorphous anodized Al oxide, mainly composed of Ti $3 \mathrm{~d}$ orbitals localized at the Ti site. This results in a linear decrease of the direct band gap from $7.3 \mathrm{eV}$ of anodic $\mathrm{Al}$ oxide to $6.2 \mathrm{eV}$ for 20 at. \% Ti-alloyed $\mathrm{Al}$ oxide. Furthermore, a low-energy absorption feature induced by Ti-derived impurity states was observed for the highest Ti-alloyed oxide films. The present results demonstrate the possibility of tuning the band gap by tailored alloying with $\mathrm{Ti}$ and provide a detailed study of the alloy-induced modification of the electronic structure of $\mathrm{Al}$ oxide.

The financial support from the Danish National Advanced Technology Foundation is greatly acknowledged. Furthermore, we would like to thank all project partners involved in the ODAAS project for their technical and scientific support. The X-ray absorption spectroscopy measurements were performed at the Micro-XAS beamline of the Swiss light source, Paul Scherrer Institute, Switzerland. The vacuum UV transmission measurements were performed on the CD1 beamline at the ASTRID synchrotron radiation facility, Aarhus University, Denmark.
${ }^{1}$ Y. Matsui, M. Hiratani, S. Kimura, and I. Asano, J. Electrochem. Soc. 152, F54 (2005)

${ }^{2}$ C.-T. Yip, M. Guo, H. Huang, L. Zhou, Y. Wang, and C. Huang, Nanoscale 4, 448 (2012).

${ }^{3}$ J. O. Song, S. R. Lee, and H. J. Shin, Appl. Phys. Lett. 86, 252501 (2005).

${ }^{4}$ M. Santamaria, F. Di Franco, F. Di Quarto, P. Skeldon, and G. E. Thompson, J. Phys. Chem. C 117, 4201 (2013).

${ }^{5}$ M. Santamaria, F. Di Quarto, and H. Habazaki, Corros. Sci. 50, 2012 (2008).

${ }^{6}$ W. Ra, M. Nakayama, H. Ikuta, Y. Uchimoto, and M. Wakihara, Appl. Phys. Lett. 84, 4364 (2004).

${ }^{7}$ C. N. Borca, S. Canulescu, F. Loviat, T. Lippert, D. Grolimund, M. Doebeli, J. Wambach, and A. Wokaun, Appl. Surf. Sci. 254, 1352 (2007).

${ }^{8}$ W. J. H. Borghols, D. Luetzenkirchen-Hecht, U. Haake, W. Chan, U. Lafont, E. M. Kelder, E. R. H. van Eck, A. P. M. Kentgens, F. M. Mulder, and M. Wagemaker, J. Electrochem. Soc. 157, A582 (2010).

${ }^{9}$ H. Habazaki, K. Shimizu, P. Skeldon, G. E. Thompson, and G. C. Wood, Thin Solid Films 300, 131 (1997).

${ }^{10}$ L. A. Fishgoit, A. D. Davydov, A. N. Kamkin, A. V. Popov, and L. L. Meshkov, Russ. J. Electrochem. 33, 1115 (1997).

${ }^{11}$ R. H. French, J. Am. Ceram. Soc. 73, 477 (1990).

${ }^{12}$ E. A. Davis and N. F. Mott, Philos. Mag. 22, 0903 (1970).

${ }^{13}$ G. K. Mor, O. K. Varghese, M. Paulose, and C. A. Grimes, Adv. Funct. Mater. 15, 1291 (2005).

${ }^{14}$ T. V. Perevalov, O. E. Tereshenko, V. A. Gritsenko, V. A. Pustovarov, A. P. Yelisseyev, C. Park, J. H. Han, and C. Lee, J. Appl. Phys. 108, 013501 (2010).

${ }^{15}$ S. Berger, H. Tsuchiya, and P. Schmuki, Chem. Mater. 20, 3245 (2008).

${ }^{16}$ K. Matsunaga, A. Nakamura, T. Yamamoto, and Y. Ikuhara, Phys. Rev. B 68, 214102 (2003). 